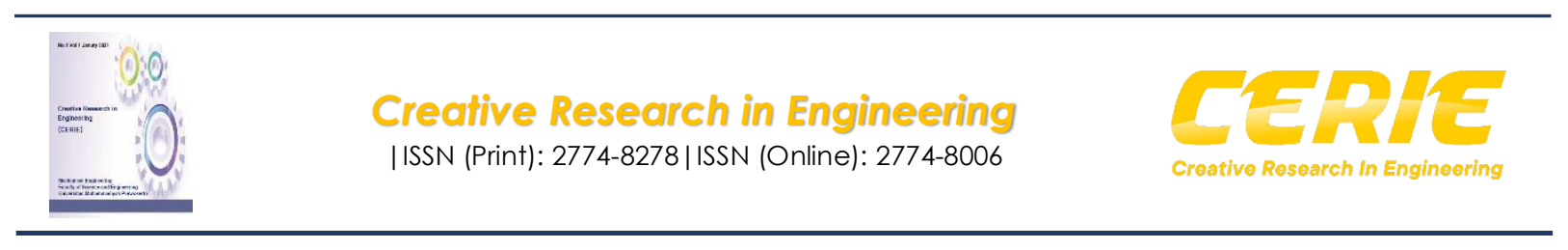

Research Article

\title{
Studi Komparasi Performa Mesin SI Berbahan Bakar Pertalite dan Plastic Pyrolysis Oil (PPO)
}

Eqwar Saputra ${ }^{1}$, dan Sunaryo ${ }^{2}$

${ }^{1}$ Teknik Mesin, Universitas Muhammadiyah Purwokerto, Indonesia

${ }^{2}$ Teknik Mesin, Universitas Sains Al-Quran Wonosobo, Indonesia

Email: Eqwarsaputra@ump.ac.id, Sunaryo@unsiq.ac.id,

Corespondensi author : Eqwarsaputra@ump.ac.id,

\section{Article History:}

Online first:

18 January 2021

Keywords: Fuel, Pyrolysis, $L D P E$

Kata Kunci: Bahan Bakar, Pyrolysis, LDPE

\section{ABSTRACT}

This study aims to evaluate the performance of gasoline engines using pure fuel (pertalite) with plastic pyrolysis oil (PPO) fuel from low-density polyethylene (LDPE) plastic waste. The test was carried out on a four stroke, single cylinder test bed machine. The research begins with the manufacture of fuel from low-density polyethylene (LDPE) plastic waste using the pyrolysis method. The performance parameters evaluated are torque, power and specific fuel consumption (BSFC). The results of the test show that the engine performance using LDPE type plastic waste fuel is relatively lower than pertalite. However, the consumption of LDPE fuel is lower than pertalite.

\section{ABSTRAK}

Karet Penelitian ini bertujuan untuk mengevaluasi unjuk kerja mesin bensin dengan menggunakan bahan bakar murni (pertalite) dengan bahan bakar plastic pyrolysis oil (PPO) dari sampah plastik tipe Low-density polyethylene (LDPE). Pengujian dilakukan pada mesin test bed empat langkah, satu silinder. Penelitian diawali dengan pembuatan bahan bakar dari sampah plastik tipe Lowdensity Polyethylene (LDPE) dengan menggunakan metode pirolisis. Parameter kinerja yang dievaluasi adalah torsi, daya dan konsumsi bahan bakar spesifik (BSFC). Hasil dari pengujian menunjukkan bahwa kinerja mesin dengan penggunaan bahan bakar sampah plastik tipe LDPE relatif lebih rendah dari pertalite. Namun, pada pemakaian konsumsi bahan bakar LDPE lebih rendah dibandingkan dengan pertalite. 


\section{PENDAHULUAN}

Mengingat krisis ekonomi global saat ini, pengembangan bahan bakar alternatif perlu ditingkatkan karena akan berdampak dimasa depan[1]. Upaya mengurangi ketergantungan energi terhadap bahan bakar fosil mulai dilakukan oleh para peneliti. Berbagai upaya telah dilakukan untuk mencari sumber alternatif bahan bakar yang ekonomis. Beberapa penelitian telah memberikan kontribusi dalam menghasilkan energi alternatif dengan biaya yang efektif, layak dikonsumsi dan ramah lingkungan. Perlu untuk memeriksa bahan bakar yang digunakan sebagai pengganti mampu dihasilkan dari sumber dan cara yang terbarukan sehingga mampu digunakan tanpa mengubah geometri mesin[2]. Diantara sumber energi yang belum sepenuhnya dimanfaatkan sebagai sumber energi adalah limbah. Salah satu limbah yang ketersediaanya berlimpah adalah limbah plastik [3]. Plastik merupakan salah satu komoditas yang sering digunakan. Diantara plastik yang paling banyak digunakan adalah polyethylene (PE), polypropylene (PP), polystyrene (PS), dan polyvinylchloride (PVC)[4]. Pada penelitian ini akan menggunakan sampah plastik tipe polyethylene. Hal ini disebabkan karena penggunaan plastik tersebut sangan banyak dalam kehidupan sehari-hari. Selain itu harganya yang murah dan mudah untuk ditemukan. Akan tetapi, dengan adanya permintaan plastik yang besar mengakibatkan limbah plastik yang menjadi ancaman pada masalah lingkungan [5]. Ada banyak metode untuk mengekstrak minyak limbah plastic dengan aman, diantaranya melalui proses pirolisis[6],[7]. Produksi bahan bakar hidrokarbon melalui proses pirolisis terbukti mampu digunakan untuk menjalankan mesin kendaraan umum [8].

Beberapa penelitian yang telah dilakukan diantara oleh Sunaryo, et al [9] melakukan pengujian kinerja pada motor bensin dengan menggunakan dua jenis bahan bakar plastic yang berbeda tipe PET dan LDPE. Hasil menunjukkan bahwa daya jenis plastik PET dan LDPE lebih rendah sebesar 3,3\% dan 14,8\% dibandingkan dengan gasoline. Selain itu, PPO menghasilkan emisi gas buang dalam bentuk HC dan CO yang lebih rendah dan konsumsi bahan bakar yang lebih efisien dibandingkan dengan bensin. Hasil ini menunjukkan bahwa minyak pirolisis limbah plastik adalah bahan bakar alternatif yang menjanjikan untuk diterapkan pada mesin SI.

Ioannis et al [3] menggunakan mesin diesel dengan campuran bahan bakar hasil pirolisis limbah plastic dengan konsentrasi 0\% hingga $100 \%$ dengan beban mesin yang berbeda. Hasil penelitian menunjukkan bahwa mesin mampu beroperasi pada beban tinggi dengan menghasilkan kinerja yang sama dengan diesel. Kumar et al [4] meneliti kinerja mesin SI silinder tunggal, dengan menggunakan bahan bakar campuran minyak pirolisis dari 0\% sampai 50\%. Menghasilkan bahwa $50 \%$ DPPO memberikan peningkatan pada kinerja mesin dibandingkan dengan campuran bensin dan DPPO lainnya di semua kondisi beban. Verma et al [5] dalam pengujiannya menunjukkan bahwa minyak plastik dapat menghemat konsumsi bahan bakar $40 \%$ tanpa kehilangan daya. Pada campuran lebih rendah dari diesel pada semua beban PPO memiliki sifat fisik yang sama jika dibandingkan dengan bahan bakar bensin[10]. Berdasarkan uraian diatas penelitian ini bertujuan untuk mengevaluasi kinerja mesin satu silinder, empat stroke, dengan membandingkan bahan bakar plastik (LDPE) dengan pertalite. 


\section{METODE PENELITIAN}

Penelitian ini memanfaatkan limbah plastik jenis LDPE. Proses pembuatan bahan bakar dengan menggunakan metode pirolisis dengan menyiapkan bahan baku dari plastik bekas yang didapat dari tempat pembuangan sampah (TPA), kemudian dilakukan pemotongan yang kecil-kecil, hal ini dilakukan supaya limbah plastik mudah terurai dalam reaktor dan hasilnya lebih maksimal, selanjutnya dicuci dan dikeringkan hingga air bekas pecucian mengering. Langkah awal yang dilakukan adalah bahan baku plastik dimasukkan ke dalam reaktor pirolisis pada temperatur $350^{\circ} \mathrm{C}$ tanpa oksigen. Cairan hasil pembakaran yang keluar dari reaktor kemudian dilewatkan ke dalam kondensor untuk mengubah uap hasil pembakaran sampah plastik menjadi cair untuk mendapatkan minyak pirolisis dari plastik (PPO).

Tabel 1. Spesifikasi Mesin

\begin{tabular}{ll}
\hline Parameter & Nilai \\
\hline Mesin & Empat langkah \\
Daya maksimal & $11.2 \mathrm{~kW} / 3600 \mathrm{rpm}$ \\
Torsi maksimal & $25.5 \mathrm{Nm} / 2500 \mathrm{rpm}$ \\
Diameter silinder & $90 \mathrm{~mm}$ \\
Langkah piston & $66 \mathrm{~mm}$ \\
Ratio Kompresi & $8: 1$ \\
Jumlah Silinder & 1 (satu) \\
\hline
\end{tabular}

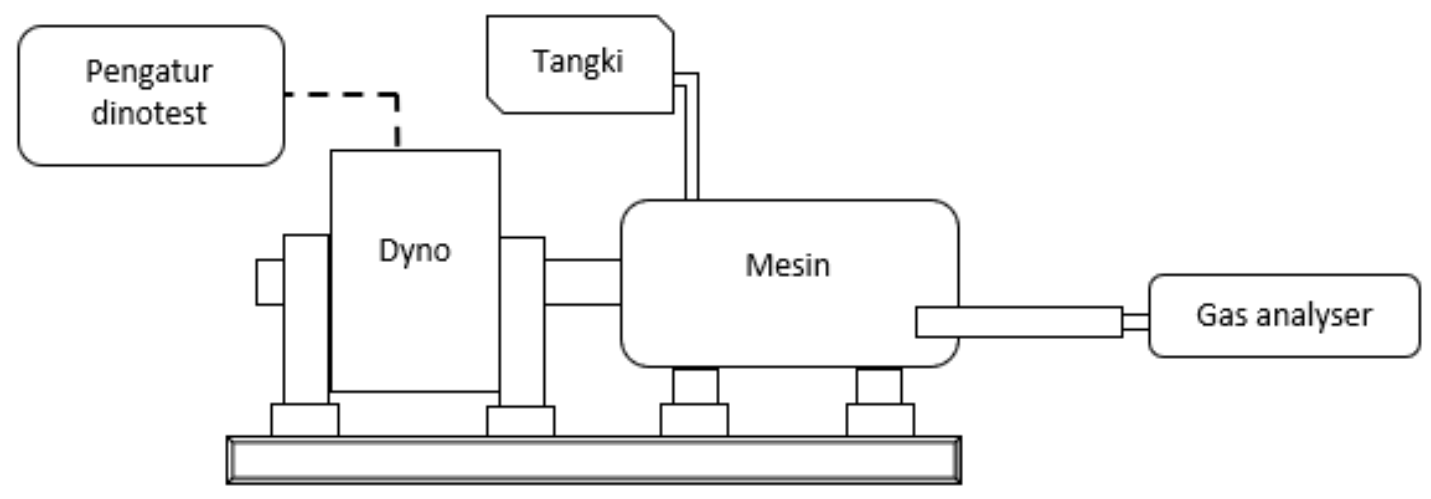

Gambar 1. Instrumen Penelitian

Pengujian menggunakan mesin test bed dengan tipe empat langkah satu silinder yang dilengkapi dengan water brake dynamometer. Bahan bakar yang digunakan pirolisis limbah plastik dan pertalite dengan variasi kecepatan mesin diantara 1300-2700 rpm dengan menaikkan secara bertahap. Kemudian diambil data adalah forcemeter, konsumsi bahan bakar, dan waktu pada masing-masing pengujian. Uji kinerja mesin SI dilakukan untuk mengetahui pengaruh penggunaan bahan bakar LDPE pada daya motor, torsi, dan konsumsi bahan bakar. 
Vol.1, No.1, Januari 2021, pp.12-18

e-ISSN: 2774-8006 | p-ISSN: 2774-8278

\section{HASIL DAN DISKUSI}

Hasil pengujian performa mesin menggunakan engine test bed sesuai dengan spesifikasi pada tabel 1. Dalam hal ini data yang dibahas meliputi torsi, daya dan konsumsi bahan bakar, sebagai berikut:

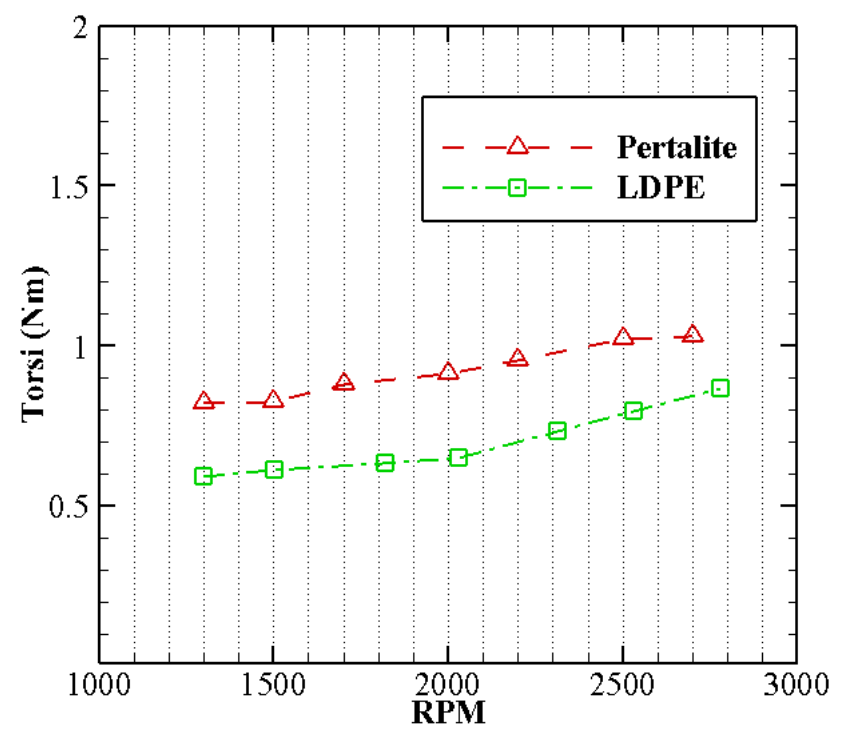

Gambar 2. Hubungan torsi dengan rpm

Gambar 2 menjelaskan hubungan antara torsi dengan kecepatan mesin pada penggunaan bahan bakar pertalite dan LDPE. Grafik torsi secara umum semua bahan bakar mengalami peningkatan seiring dengan meningkatnya putaran mesin. Putaran mesin yang semakin tinggi, maka efisiensi volumetrik semakin meningkat. Efisiensi volumetrik merupakan perbandingan jumlah udara yang terhisap dalam keadaan yang sebenarnya terhadap jumlah udara yang terhisap dalam keadaan yang ideal sebanyak volume langkah piston pada keseluruhan silinder [11]. Pengujian performa mesin dengan bahan bakar LDPE torsi mengalami penurunan sebesar 15\% pada 2780 dari bahan bakar pertalite. Hal ini disebabkan karena adanya penurunan angka oktan yang lebih kecil sehingga pembakaran yang terjadi tidak maksimal. 
Vol.1, No.1, Januari 2021, pp.12-18 e-ISSN: 2774-8006 | p-ISSN: 2774-8278

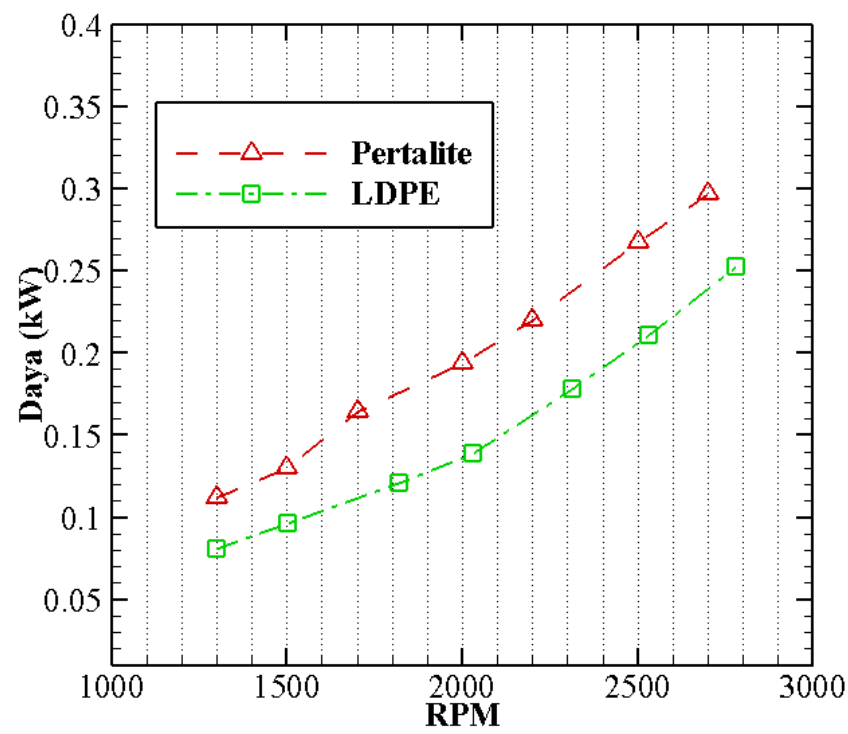

Gambar 3. Hubungan daya dengan rpm

Gambar 3 menunjukkan hubungan daya dengan kecepatan mesin pada penggunaan bahan bakar LDPE dan pertalite pada kecepatan mesin yang berbeda. Secara umum kedua bahan bakar menunjukkan tren yang sama, peningkatan putaran mesin menghasilkan daya yang semakin tinggi. Pada pengujian performa daya mesin pada penggunaan bahan bakar LDPE lebih rendah dibandingkan dengan penggunaan bahan bakar pertalite. Penurunan daya mesin sebesar 14\% lebih rendah dari pertalite pada kecepatan mesin $2780 \mathrm{rpm}$. Hal ini disebabkan karena adanya penurunan angka oktan yang lebih kecil sehingga pembakaran yang terjadi tidak sempurna. Disisi lain ada kemungkinan untuk meningkatkan daya mesin karena LDPE memiliki nilai kalor yang lebih tinggi. Selain dari angka oktan, penyebab penurunan daya kemungkinan karena tekanan silinder didalam mesin yang terlalu tinggi sehingga waktu percikan bahan bakar tidak sesuai.

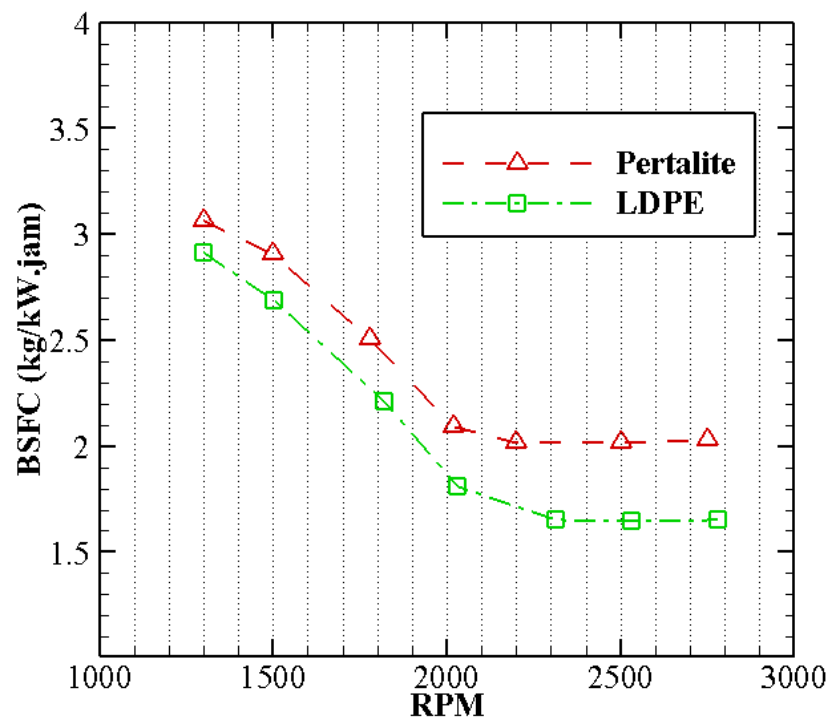

Gambar 4. Hubungan BSFC dengan rpm 
Gambar 4 menunjukkan hubungan konsumsi bahan bakar terhadap kecepatan mesin pada penggunaan bahan bakar pertalite dan LDPE. Secara umum grafik mengalami penurunan ketika kecepatan mesin meningkat. Konsumsi bahan bakar spesifik mengalami penurunan secara bertahap. Dengan penggunaan bahan bakar LDPE mampu menurunkan konsumsi bahan. Hal ini disebabkan oleh nilai kalor, kepadatan dan viskositas bahan bakar. Nilai massa jenis dan kalori campuran meningkat dengan peningkatan proporsi plastik karena minyak plastik lebih padat daripada pertalite dan juga memiliki nilai kalori yang lebih tinggi.

\section{KESIMPULAN}

Penelitian ini mengevaluasi kinerja dari mesin (SI) dengan menggunakan bahan bakar pertalite dan LDPE. Performa mesin menggunakan bahan bakar dari pirolisis sampah plastik tipe LDPE relatif lebih rendah dibandingkan pertalite. Namun, pada pemakaian konsumsi bahan bakar LDPE lebih efisien dibandingkan dengan bahan bakar pertalite.

\section{DAFTAR PUSTAKA}

[1] A. M. Pourkhesalian, A. H. Shamekhi, and F. Salimi, "Alternative fuel and gasoline in an SI engine : A comparative study of performance and emissions characteristics," Fuel, vol. 89, no. 5, pp. 10561063, 2010, doi: 10.1016/j.fuel.2009.11.025.

[2] M. Mourad and K. Mahmoud, "Investigation into SI Engine Performance Characteristics and Emissions fueled with Ethanol / Butanol-Gasoline Blends," Renew. Energy, 2019, doi: 10.1016/j.renene.2019.05.064.

[3] I. Kalargaris, G. Tian, and S. Gu, "Combustion, performance and emission analysis of a DI diesel engine using plastic pyrolysis oil," Fuel Process. Technol., vol. 157, pp. 108-115, 2017, doi: 10.1016/j.fuproc.2016.11.016.

[4] K. V. Kumar, R. K. Puli, A. Swarna Kumari, and P. Shailesh, "Performance and emission studies of a si engine using distilled plastic pyrolysis oil-petrol blends," MATEC Web Conf., vol. 45, 2016, doi: 10.1051/matecconf/20164503002.

[5] A. Verma, A. Raghuvansi, M. A. Quraishi, J. V Tirkey, and C. Verma, "Engine Fuel Production from Waste plastic Pyrolysis ( WPO ) and Performance Evaluation in a CI engine with Diesel Blend," vol. 2508, no. 6, pp. 1712-1721, 2018.

[6] P. Harshal and L. Shailendra, "Waste plastic Pyrolysis oil Alternative Fuel for CI Engine - A Review," Res. J. Eng. Sci., vol. 2, no. 2, pp. 26-30, 2013.

[7] A. K. Panda, S. Murugan, and R. K. Singh, "Performance and emission characteristics of diesel fuel produced from waste plastic oil obtained by catalytic pyrolysis of waste polypropylene," Energy Sources, Part A Recover. Util. Environ. Eff., vol. 38, no. 4, pp. 568-576, 2016, doi: 10.1080/15567036.2013.800924.

[8] N. Miskolczi, A. Angyal, L. Bartha, and I. Valkai, "Fuels by pyrolysis of waste plastics from agricultural and packaging sectors in a pilot scale reactor," Fuel Process. Technol., vol. 90, no. 78, pp. 1032-1040, 2009, doi: 10.1016/j.fuproc.2009.04.019.

[9] Sunaryo, M. Efendy, Sarjito, and N. S. Kamarrudin, "Pyrolysis of plastic waste as an alternative fuels in spark ignition engine," Int. J. Emerg. Trends Eng. Res., vol. 7, no. 11, pp. 454-459, 2019, doi: 10.30534/ijeter/2019/097112019.

[10] S. Kumar, R. Prakash, S. Murugan, and R. K. Singh, "Performance and emission analysis of blends of waste plastic oil obtained by catalytic pyrolysis of waste HDPE with diesel in a CI engine," 


\section{Creative Research in Engineering (CERIE) \\ Vol.1, No.1, Januari 2021, pp.12-18 e-ISSN: 2774-8006 | p-ISSN: 2774-8278}

Energy Convers. Manag., vol. 74, pp. 323-331, 2013, doi: 10.1016/j.enconman.2013.05.028.

[11] Arismunandar, Wiranto. 1988. "Penggerak mula motor bakar torak. Bandung: Ganesha ITB. 